\title{
Remote online exams in higher education during the COVID-19 crisis
}

Because of the COVID-19 outbreak, most higher education institutions across the OECD decided to close their campuses. As a result, teaching and assessment activities have been conducted from a distance, generally online. Based on the literature and on the experiences of the international network of higher education institutions participating in the project on Fostering and Assessing Creativity and Critical Thinking of the OECD Centre for Educational Research and Innovation (CERI), this brief outlines possible short-term and long-term solutions for organising student examinations on line in the context of campus closures and social distancing measures.

This policy brief explores the following questions:

- What are the challenges and solutions to designing and conducting end-of-term examinations on line following campus closures?

- What new forms of examinations could replace or supplement the mainstream methods in the future?

\section{General context}

Over the last few months, governments in more than 190 countries closed their educational facilities fully or partially to limit the rapid spread of COVID-19 (Giannini, Jenkins and Saavedra, 2020[1]). Higher education institutions worldwide adopted a similar response and shut down their campuses, affecting around $99 \%$ of the world's higher education student population (Malee Bassett and Arnhold, 2020[2]).

This situation has massively disrupted teaching and learning in higher education. A recent survey by the International Association of Universities (IAU) of higher education institutions across the world $(\mathrm{N}=424$, 109 countries) showed that more than $90 \%$ of the surveyed institutions have replaced classroom instruction by distance teaching and learning or are in the process of developing solutions to continue teaching and learning remotely. Around $7 \%$ of institutions reported having cancelled all teaching activities, mostly on the African continent (IAU, 2020[3]).

In the international network of 26 higher education institutions participating in the OECD-CERI project on Fostering and Assessing Creativity and Critical Thinking in Education, the majority of institutions delivered their courses remotely through online technologies. The shift to online teaching and learning raised important challenges for organising examinations and ensuring the possibility for students to progress in their studies. How do educators make sure students take their exams by themselves or without assistance? How do they assess students' proficiency in some practical or professional domains when it is difficult to 
demonstrate from a distance? How do they design remote examinations that reliably certify students' progression and add value to their learning?

The health crisis may also accelerate the development and adoption of digital and online technologies that open up promising prospects for student assessment. They allow assessing progression on a variety of skills and offer numerous opportunities to foster and demonstrate learning in new ways as compared to traditional paper-and-pencil tests (Crisp, 2011 $1_{[4]}$; Timmis et al., 2016 $6_{[5]}$; Alruwais, Wills and Wald, 2018 $8_{[6]}$ ). This potential remains largely untapped in higher education. While numerous initiatives have been launched over the last decade to integrate digital technologies in teaching and learning activities, examinations still mostly rely on traditional methods (Guàrdia, Crisp and Alsina, 2016[7]).

Many existing online programmes use exam centres for their online examinations. This is not a possible solution in a context of shutdown with strict social distancing measures. The recent shift to online course delivery in higher education requires additional solutions to be developed to measure and certify students' acquisition of knowledge and skills from a distance. Several practical solutions can be considered to adapt on-site examinations to remote online settings. Beyond these adaptations, this crisis allows for deeper reflection on how examinations could be conducted in the future.

This paper discusses avenues for designing and conducting course examinations in higher education online, notably from students' home. Its focus is on high-stake summative examinations designed by instructors to grade students and award course credits after its completion - and, ultimately, for higher education institutions to award degrees. The paper does not cover tests for admission to higher education institutions or programmes, or secondary school-leaving examinations, even though the challenges are not necessarily different. The next sections will further describe the main challenges associated with moving examinations online before exploring the solutions that can be develop to address them. The last part will explore how institutions and faculty could use the current crises to shift the examination paradigm in higher education, from a short-term adaptation to a longer-term transformation of instruction and assessment practices.

\section{Challenges associated with distance online examinations}

Following campus closures to limit the spread of COVID-19, institutions and faculties faced several challenges associated with the shift of student examinations online. While these challenges already existed before campus closures, they were exacerbated by the crisis. These included the possible increase in dishonest behaviours, difficulty in assessing practical knowledge and skills, the need to ensure a fair treatment of test takers and the risk of technical failure.

\section{Possible student academic dishonesty}

Student academic dishonesty, which in practice translates to cheating and plagiarism, is by far the most frequently discussed challenge in higher education today with regard to the shift of examinations online. Institutions and faculty have a long tradition of supervising students when taking examinations on-site. Now that courses and examinations must be delivered online, the capacity to control students' actions is reduced. Students working from home, or elsewhere, may be able to access unauthorised resources and materials, communicate with external people or even ask someone else to take examinations for them.

Higher levels of academic dishonesty are likely to reduce the reliability of higher education degrees and diplomas. Higher education institutions therefore need to develop examination strategies that limit the risk of students cheating and plagiarising when taking their examinations.

\section{Assessing and certifying practical knowledge and skills}

In some domains, student evaluations cannot rely on written tests to measure acquired knowledge and skills because direct observation of students' actual capacity to perform a practical task is required. This 
is common in disciplines with a strong professional orientation or practical component such as the arts, nursing or physical education.

Alternative forms of assessment have been developed, such as scenario-based assessments and simulations in virtual online environments in the medical field, but these are few and often costly (Ripley et al., 2009 ${ }_{[8]}$; Ryall, Judd and Gordon, 2016 $\left.{ }_{[9]}\right)$. Moreover, they are generally not sufficient to measure the acquisition of the whole set of practical skills students are expected to acquire in their courses (Rutten, Van Joolingen and Van Der Veen, 2012[10]). Assessing practical knowledge and skills through the observation of student performance when practicing a task often remains very challenging from a distance (Hannafin et al., 2003[11]).

Likewise, several degree programmes request students to acquire professional experience and knowledge by doing internships, work placements or apprenticeships. In the situation implied by the COVID-19 outbreak, such professional experiences can be difficult to complete under normal conditions. They can thus be difficult to assess and validate.

\section{Ensuring fairness}

During on-site examinations, all students gather in the same room to take a test in similar conditions (timing, available material, etc.). In the context of off-site online examinations, students do not benefit from the same working conditions. They often have different levels of technological equipment (screens sizes, computer speeds, bandwidth connections, etc.). Similarly, some might not have access to a quiet room to concentrate while taking their exams.

As they shift to online examinations, institutions need to provide students with equitable opportunities to progress in their degree. They need to check with students that they can take their examinations in suitable conditions and ensure that poorer technological equipment does not impair academic success.

\section{Risk of technical failure}

An adequate and stable technical infrastructure is a key prerequisite to organising examinations online. For institutions, this means having good servers and learning management systems. As for students and faculty members, they all need proper access to the Internet from their homes. Clearly, institutions, faculty members and students all need to benefit from a secured and reliable electricity supply.

Even with leading-edge technological infrastructure, the occurrence of technical failures during online examinations remains possible. It only takes one individual failure from one of the different interconnected sources (institutions' IT systems, Edtech companies' servers, students' individual computers or local Internet providers) to threaten the validity of an examination. Besides, this situation leaves room for dishonest students to complain and blame the technological system for a bad exam result.

In light of the risk of technical failure, technological requirements need to be kept to a minimum. Institutions and faculty can rely on simple examination tools and methods, and be flexible when setting the conditions for taking exams.

\section{Strategies for online examinations}

In light of the different challenges mentioned above, several solutions have been used in the higher education sector to conduct online examinations following campus closures. These are presented below. The examination strategies of institutions and faculty members often relied on a combination of multiple solutions. 


\section{Cancellation and postponement}

A straightforward response to the challenges of conducting examinations online is to postpone exams to a later stage when on-site activities resume, or to simply cancel them.

Around the world, several institutions have postponed examinations for different reasons. One reason is that some institutions are located in regions where the Internet is not widespread, and students face major difficulties following online courses, accessing digital learning resources or taking remote examinations. Another reason is domain-specific, as some courses rely on laboratory classes or practice-oriented activities to examine students' acquired knowledge and skills. If these activities cannot be conducted remotely, then postponement might be the most appropriate solution in the short term.

In the context of the OECD-CERI Project network, institutions have developed solutions beyond the mere postponement of final examinations by revising academic calendars and curricula. In some programmes, faculty have switched courses between academic semesters or years to teach mostly theoretical courses online and postpone those with lab classes and practicum to a future semester when on-campus teaching could resume. Such measures have the advantage of not delaying students in their academic progression, provided that it does not impact negatively their learning experience. Rather than revising academic calendars, some institutions organised catch-up periods after the end of the semester impacted by the COVID-19 crisis (e.g. during the summer break) to give students another chance to validate their courses.

In some countries, several institutions cancelled all exams for the first semester of 2020 , often because of inequity issues arising from large differences in students' Internet access (UNESCO, 2020[12]). This type of measure raises the question of the status of this semester for students' degrees. Is the semester cancelled and are students delayed in their degree progression? Conversely, do institutions allow students to progress in their degree without having to validate courses through a final exam despite the impossibility of certifying that skills and knowledge were actually acquired?

An intermediate solution to cancelling exams is to make them non-mandatory or to lower the stakes associated with examinations for students. Examples of such measures are the "no detriment polices" adopted in several universities in the United Kingdom. These policies often encompass a large set of different measures aiming to ensure that students are not disadvantaged by the change in examination rules induced by the shutdown of campuses. In practice, "no detriment policies" generally guarantee students a final course grade that is not lower than their average performance before the COVID-19 outbreak (QAA, 2020[13]).

\section{Online proctoring}

Online proctoring is a solution that has been developed to supervise remote examinations. It aims to reduce the risk of student academic dishonesty. Online proctoring relies on different technological tools that allow the identity of test takers to be verified at the beginning of the examination, student computers to be locked down to prevent access to other applications, and students to be recorded throughout the test using their webcams and microphones. A proctoring system can be monitored by a person, or a group of people who control what students do during their exam (e.g. professors, teaching assistants). Several commercial proctoring systems used in HEls around the world also rely on algorithms to supervise students. These automated technologies create alerts when they detect unusual or suspicious events, for instance when a student disappears from the screen or engages in a conversation.

Online proctoring has been used by many HEls around the world to limit the risk of students cheating in remote examinations. Yet, it has also raised a number of concerns.

A first concern relates to students' privacy, security and data protection when proctoring technologies rely on audio and video recording. A second concern is that online proctoring is not a perfect solution to prevent dishonest behaviours. Students could, for instance, use multiple devices to access the Internet and communicate with external people. Moreover, proctoring technologies require effective and stable 
functioning of IT systems, servers, students' computers and Internet connections. In practice, technical failures often occur and can have important implications for the validity of examinations. A fourth concern highlighted by participants in the OECD-CERI project is that online proctoring increases students' anxiety when taking their exam as they fear being penalised because of technical failures.

In light of these issues, and given the potentially high financial and human costs incurred by online proctoring, several institutions advise their faculty members to avoid using proctoring systems and to try to prevent academic dishonesty through other means. Some recommend communicating an institutional code of ethics opposing cheating behaviours and plagiarism. Honour codes can be integrated in course syllabi or translated into a statement that every student needs to sign when entering a course or before taking an examination. Several studies have found that such preventive measures can indeed help prevent academic dishonesty (McCabe and Treviño, 2002[14]; Teixeira and Rocha, 2010[15]).

\section{Redesigning examinations}

Examination redesign is a solution to several challenges associated with the shift to remote online assessment. It encompasses many different types of adaptations that can be combined to create appropriate examination models for the specific context of institutions, faculties, students or courses. The following list highlights the most frequently encountered solutions in the literature and in recommendations issued by higher education institutions to help faculty members cope with the implications of the COVID19 crisis.

- Oral examinations. Examinations that were initially planned as written final exams can be redesigned as synchronous oral exams. These offer several advantages to limit student cheating, cope with the risk of technical failure and ensure that assessment and grading can, where appropriate, be adjusted to students' individual situations and constraints. Yet, oral exams often require a significant time investment from faculty members, in particular when they are in charge of assessing large groups of students. In such circumstances, alternative solutions could be considered such as relying on additional academic staff to assess students (e.g. teaching assistants or $\mathrm{PhD}$ students), reducing the length of examinations or, in domains where it is appropriate, conducting group oral examinations (e.g. in a foreign language course).

- Flexible modes of examination. Introducing flexibility in the mode of examination is a way to accommodate students' individual specificities and address the issue of fairness. It involves giving students the ability to choose their preferred mode of examination between different options, for instance an oral exam or a proctored written test. These different modes of examinations should be comparable to ensure a fair treatment of all students (e.g. by having the same requirements and levels of difficulty). This flexibility can also be a way to reduce student anxiety with high-stakes examinations, which could in turn help reducing dishonest behaviours (Davis et al., 1992[16]; Hollinger and Lanza-Kaduce, 2009 $[17])$.

- Varying sets of exam questions. Administering different sets of exam questions to different students in a written online examination reduces the risk of student interacting with each other. This solution requires additional investment from exam developers as it implies designing and scoring a larger range of questions. Besides, it is important that the questions taken by different students measure the same constructs and have the same level of difficulty to ensure the reliability and fairness of the evaluation. An alternative solution is to use the same questions for all students but randomise their order in individual exams. When exams rely on multiple-choice questions, the order of response items within each question can also be randomised. Most applications for online assessments offer that possibility. Differentiating exam questions or randomising their order is a way to address possible dishonest behaviours without having to use proctoring technologies. Yet, it is only helpful in limiting student interactions and is not effective for other forms of cheating or plagiarism (e.g. copying and pasting text form the Internet). 
- Reduced time limits. Setting stricter time limits for the duration of written examinations is another way to prevent possible dishonest behaviours. While it does not prevent students from interacting with each other or looking for answers using unauthorised means, it can discourage dishonest behaviours when the time devoted to cheating competes with the time needed to answer exam questions. In this respect, exam durations can be set so that the highest performing students would have just enough time to complete the test within the time limits while average performers would only be able to answer between 60 to $80 \%$ of the questions. In this context, scoring methods could be adapted and students would need to be informed in advance of adaptations made to the examination. Besides, it is important to ensure a fair treatment of students in such online examinations, as they do not always take their exams under the same conditions (e.g. with regard to the speed of their Internet connections, the devices available to take examinations, their housing conditions, etc.). Assuming that these requirements are met, reducing the time limits of exams can be a way to address academic dishonesty without relying on proctoring technologies.

- Open book written examinations. Allowing students to access the course material and the Internet during an examination eliminates the risk of students cheating by consulting unauthorised resources. To prevent students from interacting with each other or asking someone else to take their exam for them, examiners could consider limiting response time or designing questions for which students need to reflect on their personal situation or their own experience with the course. Open book examinations are usually not appropriate when they comprise memorisation questions whose answer can be directly copied and pasted from the course or book. Rather, they are more suited to assess students' mastery of the course content and capacity to think at higher cognitive levels (Eilertsen and Valdermo, 2000[18]; Olt, 2002[199]). Questions could, for instance, require students to write an essay on a controversial issue, analyse and interpret data, or solve a realworld problem. Open-book questions can also rely on multiple-choice questions that are designed in such a way that students need to apply their knowledge and engage in deep thinking to find the right answers (Haladyna, 2011 [20]; Kerkman and Johnson, 2014[21]). One advantage of multiplechoice questions is that they eliminate the risk of plagiarism.

\section{Substituting examinations with other forms of assessment}

Substituting final examinations with alternative models for student assessment is a fourth type of solution to the challenges associated with organising remote examinations. Like examination redesign, it implies adapting assessment methods to better accommodate the conditions of online course delivery. Unlike examination redesign, it is not limited to a revision of the format of a specific exam but consists of rethinking the entire model of student assessment and examination in a course, for instance by replacing a final highstake written exam with a semester-long student research project.

\section{Using project assignments to certify students' knowledge and skills}

There are numerous modes of assessment that can be considered by institutions and faculty members to replace final examinations. A large part of these consists of asynchronous and untimed project assignments that require students to generate an original product. Such assignments are generally open book and can be individual or collaborative. Sometimes they culminate with students performing a specific task to demonstrate their knowledge and proficiency. Common examples of asynchronous project assignments used in online courses include:

- Written assignments such as argumentative essays, synthesis papers, critical analysis, blog posts and student diaries.

- Online interactions between students through discussions on blogs, wikis or forums.

- Research projects for which students need to carry out fieldwork, collect data or conduct interviews. Such projects often end with a written report or the production of an artefact. 
- Student presentations of the outcomes of asynchronous assignments. These can be done synchronously in front of the class or asynchronously through podcasts, video recordings, or any other type of multimedia product.

Asynchronous project assignments are particularly well adapted to online course delivery. In a study on 24 online course syllabi, Kearns showed that most courses rely on these types of assignments to assess and grade students (Kearns, 2012[22]). More precisely, only a third of the courses relied on tests and exams and, when they did, the average weights of these tests in final course grade was less than $50 \%$. On the other hand, written assignments and online discussions were used in respectively $92 \%$ and $80 \%$ of courses to assess and grade students in online settings.

The advantages of using asynchronous project assignments for student assessment are multiple. As with open-book examinations, they eliminate de facto several benefits of behaving dishonestly. As students are required to produce an original output, there is no need to prevent them from using the resources of their choice or interacting with their peers. Peer collaboration and autonomous research are conducive to learning and asynchronous project assignments allow students to strengthen those skills. Besides, requiring students to present their work in front of the class can limit their ability to ask someone else to do their assignment for them (or at least allows this to be detected). In addition, students have more flexibility to respond to evaluation requirements. As project assignments are asynchronous and untimed, students can choose to "take" them at the time and in the conditions that best fit their own individual constraints. In this respect, asynchronous project assignments can mitigate the risk of unfair treatment of students in online assessments.

Plagiarism is still an important form of dishonest behaviour that can occur in the context of asynchronous project assignments. Several techniques can be used to limit the risk of plagiarism (Audet, 2011 [23]): using a plagiarism detection software, focussing on topical issues or questions that are directly related to students' personal interest, imposing the use of a minimal number of recent resources, concluding assignments with a synchronous presentation followed by questions and answers from the instructor and the class, etc.

\section{Taking advantage of the features of online environments}

Beyond the types of student assessment, the transition to online course delivery calls into question the traditional model of assessment through high-stakes final examinations. Online teaching and learning allows the implementation of a diversity of instruction approaches and leaves much more trace than faceto-face education. This creates new opportunities for a continuous assessment of students throughout academic semesters. Many instructors who started delivering online courses well before the COVID-19 outbreak took advantage of these new conditions by administering a variety of assignments and tests on a regular basis (Gaytan and McEwen, 2007[24]; Martin et al., 2019[25]). Several methods can be used to assess students regularly such as small timed quizzes, asynchronous discussions on forums, semesterlong projects with intermediate milestones, portfolios, peer-evaluations, etc. While these methods are well suited for online course delivery, they can also bring about important benefits for face-to-face courses.

With careful planning so as to maintain an appropriate workload for both students and faculty, multiple moments of assessment can be a powerful solution to address the challenges associated with the shift toward online course delivery (Swearingen, 2002[26]; Arend, 2007[27]). A reasonable number of regular assessments are less likely to generate stress and anxiety among students than final examinations that have a considerable weight in the course grade, hence limiting the risk of academic dishonesty. The assessment framework and student-teacher relationships also reduce the possibility of students asking someone else to take their assessment for them. Besides, following student progress from the first weeks of a course allows faculty members to identify those who are coping with difficult studying conditions and explore solutions with them. 


\section{What's next for student examinations online?}

Adapting student examinations to online administration requires institutions and faculty to carefully consider several parameters: the nature of courses and domains, the intended learning outcomes, their own capacities and resources and the specificities of students' individual contexts. Furthermore, organising examinations in online settings is likely to be done very differently depending on faculty members' previous experience with online teaching, whether they have sufficient time to prepare, or if they need to respond to an abrupt disruption that requires a sudden change of plans. In this respect, the recent shift towards online examinations resulting from the COVID-19 outbreak could lead to very different examinations models between, for example, the first semester of 2020 and the academic year 2020-2021 (in the northern hemisphere).

\section{Remote online examinations when there is little time for preparation}

The sudden shift to online assessment implies adapting examinations that were initially planned to be conducted face-to-face. In this context, faculty members and institutions may have limited capacity to change the format of the examination because of legal or institutional requirements, or because they have too little experience teaching and assessing in online settings. Unexpected and hasty changes to examination frameworks that do not take fully into account the pros and cons of different solutions in different contexts could have negative repercussions on the validity of examinations and the credibility of certifications. It could also lead to higher levels of student stress and anxiety when taking an examination and increase the risk of leaving some students behind. When traditional final examinations cannot be avoided, institutions and faculty members could consider several solutions to organise them online. Where possible, the model of examination could be adapted. Otherwise, specific adjustments can be made to existing written examinations. The following measures could be considered to adapt or adjust examinations when there is little time for preparation:

\section{Adapting the model of examination}

- Rely on oral examinations where possible.

- Introduce flexibility in the modes of examination (e.g. letting student choose between an oral exam or a proctored online written exam).

- Set up effective communication channels between institutions and students (e.g. a dedicated call centre for students anticipating or experiencing issues with online examinations).

- Inform students about expectations, the format of examination and the grading modalities clearly and well in advance. As students are experiencing a lot of stress and pressure in the current situation, seeing that their professor is in control and understanding what is expected from them is a way to strengthen their confidence and agency, and prevent possible dishonest behaviours (Harrison, 2020[28]).

- Exceptionally, give students who face difficult working conditions at home the opportunity to take their exam on campus with appropriate social distancing measures (if this is legally possible).

\section{Adjusting existing written examinations}

- Invite students to sign a statement on academic integrity before taking their examinations.

- Set strict time limits so that cheating becomes less practical as it implies having less time to complete the exam. Grading scales might be adapted accordingly and students should be well informed of changes to the examination format.

- Design questions that require students to think or analyse information rather than merely recall content knowledge. Avoid questions whose answers can be found easily using a web search engine. 
- Give different sets of questions to different students, or randomise the order of questions (and inquestion items).

- Consider organising open-book and open-web examinations and redesign examinations accordingly (e.g. requiring students to apply their knowledge and analyse, synthesise or evaluate information).

- Use online proctoring systems after having closely considered their possible adverse impacts and taken appropriate measures to prevent these (e.g. adopting a general procedure to respond to possible technical failures).

\section{Remote online examinations when there is time for preparation}

The online environment offers new opportunities for student assessment as compared to on-site testing. To fully seize these opportunities, institutions and faculty members will not only need to redesign existing examinations, but to rethink the whole process of assessment. The coming months offer the possibility to plan a deeper revision of examination models for the next academic year as online teaching and assessment will likely remain the norm in many institutions worldwide, at least for part of their courses.

Two types of solutions are worth exploring while planning online examinations when there is time for preparation: multiplying assessment instances and reconsidering the constructs of examinations.

\section{Towards multiple assessments}

Multiplying assessment instances amounts to relying on a diversity of regular assignments and tests to measure and certify student learning. This is facilitated by the variety of assessment formats that can be used in online environments. Online environments also allow instructors to implement practices that would be almost inconceivable face-to-face: they can record students at specific times (upon consent), monitor discussions in different groups, collect additional data during teaching and learning activities, etc. The online environment offers new opportunities and new metrics that do not exist in traditional classroom environments and instructors could rely on those to explore additional types of assessments and examinations.

Multiplying assessments throughout the duration of a course offers several advantages. On the one hand, it relieves some of the stress and pressure that students often face when taking high-stakes examinations and that can prompt dishonest behaviours: while the assessments remain high stake, there are chances to offset a bad performance. In the context of multiple and regular assessments, the weight assigned to each individual test or assignment in the total course grade can be lower than the weight of a single final examination. On the other hand, regular assessment also gives a better picture of student learning. It allows a broader set of skills and knowledge to be covered and instructors can follow students' progression in learning over time rather than only after the completion of courses.

Beyond the role of assessment in certifying students' acquisition of specific knowledge and skills, multiplying assessment instances can thus bring large benefits for the learning process itself by adding a formative dimension to summative assessments. Regular assessments allow students to receive individual feedback on their learning and, if needed, adapt their learning strategy to better meet the course requirements. Feedback can take the form of a simple grade or, ideally, of constructive comments that guide students in their learning. Where instructors have a limited capacity to provide constructive feedback to each individual student (e.g. if they teach to large groups), online and computer-based technologies could also be used to formulate such feedback in a more automated way, for instance by using algorithms or systems powered by artificial intelligence (Vincent-Lancrin, 2020[29]). In such circumstances, instructors might also consider using self-assessment or peer-assessment to multiply students' opportunities to receive feedback on their learning. 


\section{Reconsidering the construct of examinations}

Reconsidering the construct of examinations implies reflecting on the types of knowledge and skills that they aim to measure. An important principle of assessment design is to ensure the alignment between the construct of a course assessment framework and its intended learning outcomes (Biggs, 2003[30]). In other words, a course examination should be designed in such a way that it measures what students are expected to learn from this course. Only then is the examination relevant to certify that students have acquired the learning outcomes that a course purports to impart.

While higher education is expected to cultivate students' deep knowledge and skills, current forms of examinations too often measure students' mere capacity to recall memorised course content rather than their ability to apply this knowledge and solve real problems. The misalignment between a course examination and intended learning outcomes impairs the capacity of the examination to certify students' acquisition of these learning outcomes. However, it is not the only problem. Assessment is also an important driver of learning: what is not assessed is not valued and therefore less likely to be learned. If students in higher education are expected to become creative problem-solvers and critical thinkers, then examinations need to measure the actual acquisition of these skills.

The shift to online assessment provides an opportunity to reconsider the construct of examinations. Some types of assessment that are implementable in online environments can be relevant to measure student progression on a variety of different learning outcomes, including their capacity to analyse, evaluate or synthesise information. For instance, conducting regular evaluations and using different assessment formats allows a broader set of knowledge and skills to be assessed. Likewise, semester-long project assignments can support the assessment of students' critical ability to master the course concepts and ideas, as well as their creativity in producing relevant and original outputs. These alternative types of assessment are also appropriate to limit the risks of student fraud and inequity due to different levels of access to technology.

The move towards online examinations induced by the COVID-19 crises has already called - and will likely continue to call - for considerable efforts from faculty members and higher education institutions to design reliable online examinations and assessments for certification. Yet, these efforts could contribute to the development of assessment formats that also enable the assessment and fostering of students' higher order thinking skills such as creativity and critical thinking. Such developments would not only strengthen the credibility of higher education degrees, it would also improve students' learning experiences and outcomes in higher education. 


\section{Fostering and assessing student's creativity and critical thinking}

This document was prepared by the team working on the Fostering Creativity and Critical Thinking in Higher Education Project at the OECD Centre for Educational Research and Innovation (CERI).

The project works with 26 higher education institutions from 14 countries to investigate ways to develop "transversal" skills that top the priorities of employers. It documented how higher education institutions and ministries

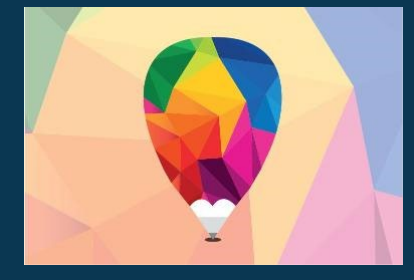
participating in the project have continued to work in a fully online or blended learning environment during and post the COVID-19 crisis, and what challenges and opportunities institutions have faced in this new context to improve students' teaching, learning and assessment. It did so through a series of interviews, questionnaires and webinars.

For more information

Contact: Mathias Bouckaert, Analyst, Mathias.Bouckaert@oecd.org; Stéphan Vincent-Lancrin, Senior Analyst and Project Leader, Stephan.Vincent-Lancrin@oecd.org

See: Fostering and assessing students' creative and critical thinking skills in higher education

\section{References}

Alruwais, N., G. Wills and M. Wald (2018), "Advantages and challenges of using e-assessment", International Journal of Information and Education Technology, Vol. 8/1, pp. 34-37.

Arend, B. (2007), "Course assessment practices and student learning strategies in online courses", Journal of Asynchronous Learning Networks, Vol. 11/4, pp. 3-17.

Audet, L. (2011), Les pratiques et défis de l'évaluation en ligne, REFAD, Montréal.

Biggs, J. (2003), "Aligning teaching for constructing learning (online)", The Higher Education Academy.

Crisp, G. (2011), Teacher's Handbook on e-Assessment, Australian Learning and Teaching Council.

Davis, S. et al. (1992), "Academic Dishonesty: Prevalence, Determinants, Techniques, and Punishments", Teaching of Psychology, Vol. 19/1, pp. 16-20.

Eilertsen, T. and O. Valdermo (2000), "Open-book assessment: A contribution to improved learning?", Studies in Educational Evaluation, Vol. 26/2, pp. 91-103.

Gaytan, J. and B. McEwen (2007), "Effective online instructional and assessment strategies", American Journal of Distance Education, Vol. 21/3, pp. 117-132, http://dx.doi.org/10.1080/08923640701341653.

Giannini, S., S. Jenkins and J. Saavedra (2020), "Reopening schools: When, where and how?”, UNESCO, https://en.unesco.org/news/reopening-schools-when-where-and-how.

Guàrdia, L., G. Crisp and I. Alsina (2016), "Trends and challenges of e-assessment to enhance student learning in higher education”, in Cano, E. and G. Ion (eds.), Innovative Practices for Higher Education 
Assessment and Measurement, IGI Global, Hershey, PA, http://dx.doi.org/10.4018/978-1-5225-05310.ch003.

Haladyna, T. (2011), Developing and validating multiple-choice test items, third edition, Routledge, New York.

Hannafin, M. et al. (2003), "Cognitive and learning factors in web-based distance learning environments", in Moore, M. and W. Anderson (eds.), Handbook of distance education, LEA Publishers, Mahwah, NJ.

Harrison, D. (2020), "Online education and authentic assessment”, Inside Higher Ed.

Hollinger, R. and L. Lanza-Kaduce (2009), "Academic Dishonesty and the Perceived Effectiveness of Countermeasures: An Empirical Survey of Cheating at a Major Public University", NASPA Journal, Vol. 46/4, pp. 587-602.

IAU (2020), The Impact of Covid-19 on Higher Education around the World, International Association of Universities, Paris, https://www.iauaiu.net/IMG/pdf/iau covid19 and he survey report final may 2020.pdf.

Kearns, L. (2012), "Student assessment in online learning: Challenges and effective practices", MERLOT Journal of Online Learning and Teaching, Vol. 8/3, pp. 198-208.

Kerkman, D. and A. Johnson (2014), "Challenging multiple-choice questions to engage critical thinking", InSight : A Journal of Scholarly Teaching, Vol. 9, pp. 92-97.

Malee Bassett, R. and N. Arnhold (2020), "COVID-19's immense impact on equity in tertiary education", World Bank Blogs, https://blogs.worldbank.org/education/covid-19s-immense-impact-equity-tertiaryeducation.

Martin, F. et al. (2019), "Award-winning faculty online teaching practices: Course design, assessment and evaluation, and facilitation", Internet and Higher Education, Vol. 42, pp. 34-43.

McCabe, D. and L. Treviño (2002), "Honesty and honor codes", Academe, Vol. 88/1, pp. 37-41.

Olt, M. (2002), "Ethics and Distance Education : Strategies for Minimizing Academic Dishonesty in Online Assessment”, Online Journal of Distance Learning Administration, Vol. 5/3, pp. 1-7.

QAA (2020), “'No Detriment' Policies: An Overview”, COVID-19 Supporting Resources, The Quality Assurance Agency for Higher Education, Gloucester.

Ripley, M. et al. (2009), Review of Advanced e-Assessment Techniques (RAeAT): final report, JISC, London.

Rutten, N., W. Van Joolingen and J. Van Der Veen (2012), "The learning effects of computer simulations in science education”, Computers and Education, Vol. 58/1, pp. 136-153.

Ryall, T., B. Judd and C. Gordon (2016), "Simulation-based assessments in health professional education: A systematic review”, Journal of Multidisciplinary Healthcare, Vol. 9, pp. 69-82.

Swearingen, R. (2002), “A primer: Diagnostic, formative, \&amp; summative assessment”, Heritage University.

Teixeira, A. and M. Rocha (2010), "Cheating by economics and business undergraduate students: An exploratory international assessment”, Higher Education, Vol. 59/6, pp. 663-701.

Timmis, S. et al. (2016), "Rethinking assessment in a digital age: opportunities, challenges and risks", British Educational Research Journal, Vol. 42/3, pp. 454-476.

UNESCO (2020), "Exams and assessments in COVID-19 crisis: fairness at the centre", UNESCO. 
Vincent-Lancrin, S. (2020), Coronavirus and the future of learning: What Al could have made possible, OECD Education and Skills Today, Paris, https://oecdedutoday.com/coronavirus-future-learningartificial-intelligence-ai/.

This work is published under the responsibility of the Secretary-General of the OECD. The opinions expressed and arguments employed herein do not necessarily reflect the official views of OECD member countries.

This document, as well as any data and any map included herein, are without prejudice to the status of or sovereignty over any territory, to the delimitation of international frontiers and boundaries and to the name of any territory, city or area.

The statistical data for Israel are supplied by and are under the responsibility of the relevant Israeli authorities. The use of such data by the OECD is without prejudice to the status of the Golan Heights, East Jerusalem and Israeli settlements in the West Bank under the terms of international law.

You can copy, download or print OECD content for your own use, and you can include excerpts from OECD publications, databases and multimedia products in your own documents, presentations, blogs, websites and teaching materials, provided that suitable acknowledgment of OECD as source and copyright owner is given. All requests for commercial use and translation rights should be submitted to rights@oecd.org. 